\title{
AN EXPLORATORY STUDY OF NANTOU ANCIENT VILLAGE REVITALISATION FOCUSING ON VISUAL, COGNITIVE AND STRUCTURAL ASPECTS
}

\author{
JAKSA NIKODIJEVIC', MILICA GRUJIC²
}

\author{
${ }^{1}$ Technical University of Vienna, Faculty of Architecture and Spatial Planning, Karlsplatz \\ 13, 1040 Vienna, Austria, ${ }^{2}$ Independent researcher \\ Theme of the dissertation: CCJQ (Creative Industrial Clusters) influence on urban \\ development of City Shenzhen in period after 2007 \\ e0925861@student.tuwien.ac.at; ryuzakilee27@outlook.com; \\ milicajnikolic@yahoo.com
}

\begin{abstract}
In the absence of spatial diversity, there is a need for additional elements that will enable the recognition of the space in which we are. These elements are landmarks. In order for a certain thing to be considered a landmark, it must be unique and recognisable either by its properties (size, shape, colour, materialisation, etc.) or by the location where it is located in space. Landmarks and zones with a strong character provide a strong identification of the space with its peculiarity.
\end{abstract}

This paper analyses the identity of the urban settlement of Nantou Old Town as a historical cluster located in the attractive location in the Nanshan District of Shenzhen City, with over 800 residential and commercial units.

The study was conducted experimentally on a number of respondents who are regular or occasional consumers in Nantou settlement, through a closed questionnaire, from which we got answers to the initial questions: how successful is the revitalisation of this cultural-historical settlement, what are the landmarks, how simple is orientation through the settlement and what method is most common in wayfinding (landmark or navigation app), does a consumer's choice in wayfinding device and landmark physical characteristics (colour, texture and form) depend on personal dimensions (gender, age, educational level and familiarity with environment).

KEY WORDS: wayfinding, landmarks, navigation app, Shenzhen City, Nantou ancient village 

visual, cognitive and structural aspects. Jaksa Nikodijevic, Milica Grujic

\section{Introduction}

The term wayfinding (WF) was first used by Lynch (1960) in the context of maps, street numbers, and directional signs as "way-finding" devices. His work, as many have seen, was considered basic in understanding the environment, and based on the concept of spatial organisation and its precondition of the cognitive map.

Siegel and White (1975) believe that levels of cognitive mapping begin with landmarks, while knowledge of space landmarks precedes knowledge of pathways in spaces, and both precede knowledge of space configuration. Some people rely only on landmarks to master a space and identify the position of adjacent spaces (Ornstein, 1992), or, more accurately, understand a space if there are visual landmarks in it Weisman (1979).

In order for a certain object (item or settlement) to be considered a landmark, it must be unique and recognisable either by its properties (size, shape, colour etc.), or by its location in a space. Lynch (1960) defined landmarks as points of reference external to the observer that should exhibit clear form and contrast with the background. For example, an area of greenery or tall buildings can be considered a landmark. However, as nature changes or other buildings emerge in the environment, the landmark may lose that function as a reference point (Richter and Winter, 2014).

In many cases, the landmarks are located at significant intersections or in places where there is a change in the direction of movement.

The property that turns a conventional geographic object into a landmark is called salience (Raubal and Winter, 2002). Landmark salience is not the same for every person, and dependent on parameters such as age, gender, education, or familiarity of the traveller with an environment (Lynch, 1960; Winter et al., 2012).

It is also important to emphasise that only the meaning of an object and its cultural, political, or social impact on people can also make an entity recognisable (Caduf and Timpf, 2008; Couclelis et al., 1987; Sorrows and Hirtle, 1999). Nuhn (2020) proposed that personal dimensions of landmarks can be analysed using measures: prior spatial knowledge and personal interests such as cultural, historical etc.

Therefore, research conducted in Shenzhen would have to take into consideration its short history and still developing visual, cultural and social identity. This city, after being selected as one of the first Special Economic Zones (SEZs) in 1979, which was "a decision that changed the future of this small frontier town in a single stroke" (Zhang, 
2008), grew in population to 10 million by the year 2013 (Shenzhen Municipal Statistic Bureau (SMSB). The exacerbation of urbanisation in Shenzhen has resulted in an intertwined layering with a complex pattern: the historical town is embedded in the urban village, which is again encircled by the city -"village in city, city in village" (https://urbannext.net/nantou-old-town/ ). The oldest "village in city"- Nantou Old Town, founded as a city over 1,700 years ago during the Jin Dynasty, was recently revitalised by one of the leading China market development groups, Vanke. However, revitalisation didn't interfere with the urban plan or result in traffic intervention, as this site remained inaccessible for vehicles.

In recent years, there has been a growing interest in using mobile applications to make the wayfinding process easier. Pedestrians rely on visual landmarks (Michon and Denis, 2001; Rehrl et al., 2009). By choosing the right landmark, we can improve future navigation applications.

In this paper, we will focus on finding the way with the help of a landmark, as well as whether people use navigation applications to help find their way. The goal is to determine which entities are targeted as landmarks, as well as their characteristics - colour, shape and form, texture, position in the settlement. Also, whether the preferences in the choice depend on gender, age, education, and familiarity with the environment. The proper definition of a landmark in Nantou settlement will contribute to the improvement of navigation applications, which, as the study showed, are slowly taking over as the main means to find a way for the domicile population.

Quantitative research was used, where the respondents were provided with visual stimuli to which they gave web-based answers. Questionnaire techniques were used in the research. The questionnaire consists of 25 closed-ended questions (the translated questionnaire is provided in appendix i).

\section{Methodology}

A quantitative research method, where subjects are exposed to visual stimuli to which they give web-based responses, was employed. Questionnaire techniques were used in the research. The questionnaire consists of 25 closed-ended questions.

The questionnaire was assembled upon 3 visits to Nantou Old Town and interviews with design and planning representatives involved in the revitalisation process. Proposed landmarks for surveyors were selected by uniqueness of space or building, position, and/or function. 

visual, cognitive and structural aspects. Jaksa Nikodijevic, Milica Grujic

Besides the respondent's profile (gender, age, education, familiarity), the questionnaire also notes whether they work/live on site, and the number and time of their visits, due to the fact that, in the period up to the autumn of 2020, the east-west road inside Nantou old Town was under construction.

The same, or similar, selected potential landmarks are tested in visual effectiveness, design attraction and also how often they were employed as wayfinding actors.

The questionnaire was completed by a total of 53 respondents. The survey was conducted on site at Nantou Old Town to random responders, voluntary responders from design \& lifestyle webchat groups and art and educational institutions (Xiao yan art school and Drama English learning studio).

Selected landmarks from the questionnaire are marked on the map. (Figure 1)

\section{Findings}

The data relates to 53 Nantou Ancient Village consumers. There were 38 female and 15 male respondents. (Appendix ii, page 2)

Most respondents were aged from 25-30 and 31-40 - 35.85\%, then from 18-24 $22.64 \%$, ages $41-50-3.77 \%$ and $51-60-1.89 \%$. One interesting finding was that no respondents were from the under 18 and above 61 age groups. (Appendix ii, page 3)

Concerning the degree of education, most responders were highly educated, Master's degree and above $43.40 \%$, Bachelor degree $41.51 \%$, College degree $9.43 \%$, high school $3.77 \%$, primary school and below $1.89 \%$ and no one was in the junior high school level group. (Appendix ii, page 4)

The lines of work were very varied as can be seen in the graph (Appendix ii, page 5), but most were from the civil service, and most were currently working as ordinary staff. (Appendix ii, page 6)

Almost half of the respondents, 26, were linked to everyday life in Nantou Ancient village, working or living there, while the other 27 had no connection. (Appendix ii, page 7)

More than half of the respondents, 28, had visited the village only once, while 16 had visited the village 2-5 times, which means that they were unfamiliar with the environment. Only 9 respondents had visited Nantou more than 5 times. (Appendix ii, page 8) 
The purpose of visit was most often leisure/sightseeing - 39 respondents, 9 had visited for an event, 5 for a group gathering and 3 for some other purpose (Appendix ii, page 9). The time of visit was mostly Spring 2021 - 33 respondents, then Winter $2021-17$ respondents and only 3 in the Autumn and Winter 2020 period. (Appendix ii, page 10)

Most respondents described Nantou Ancient Village as a Creative Cluster - 35 \%, and the least number described it as a tourist attraction - 13\% (Appendix ii, page11).

All respondents described the revitalisation of Nantou Ancient City as either very successful - 12, or successful - 41 (Appendix ii, page 12).

The new Nantou visual experience is described mostly as Mixed culture - 29 respondents, Design/function - 17 respondents, Unique - 5 respondents, and 2 respondents described it as Generic (Appendix ii, page 13).

The quality of orientation and site finding inside Nantou Ancient Village is mostly marked as understandable - 34 respondents, easy to understand 15 , and as complex by 4 respondents (Appendix ii, page 14).

The main purpose was to examine: 1 . how consumers find their way from point $\mathrm{A}$ to point $\mathrm{B}$, by using landmarks or navigation apps, which also rely on landmarks, 2 . which landmarks are singled out as most attractive and useful by investigating their physical characteristic - colour, texture and form, and 3. which landmarks help consumers to find their way.

The independent variables were gender, age, educational level and familiarity with environment.

Question 1: Does the consumer's choice in wayfinding devices - landmarks or navigation app, depend on gender, age, educational level and familiarity with environment?

Question 2: Is the choice of landmarks based on their physical characteristics (colour, texture and form) dependent on gender, age, educational level and familiarity with environment?

1. We found that $100 \%$ of consumers used a navigation app in finding their way, regardless of their user profile. 42 respondents said that landmarks helped them to locate or find their way, however, they chose a navigation app as the most effective wayfinding device. (Appendix ii, Page 38) 

visual, cognitive and structural aspects. Jaksa Nikodijevic, Milica Grujic

2. We found that the most important physical characteristic of landmarks was shape or form - 29 respondents, followed by texture and patterns - 16 respondents, and colour 8 respondents.

3. We found that preference in physical characteristics of landmarks doesn't depend on gender. Both genders picked shape as the main characteristic, then colour and the smaller percentage chose texture ( Figure 2).

4. We found that preference in physical characteristic of landmarks depends on age (Figure 2).

18-24 - all three parameters were chosen by the same number of respondents, 4 for each parameter.

25-30 - they chose shape as the dominant parameter

31-40 - they also chose shape as the dominant parameter

41-50 - all respondents chose texture

51-60 - all respondents chose texture

5. We found that preference in the physical characteristic of landmarks didn't depend on the degree of education. All categories of educational degree mostly picked shape as the dominant parameter (Figure 2).

6. We found that preference in the physical characteristic of landmarks didn't depend on familiarity with environment (shown by number of visits). All categories picked shape as the major parameter (Figure 2).

7. Based on the figures in Appendix ii (page 16 - 35), we identified influential landmarks in Nantou Old Town.

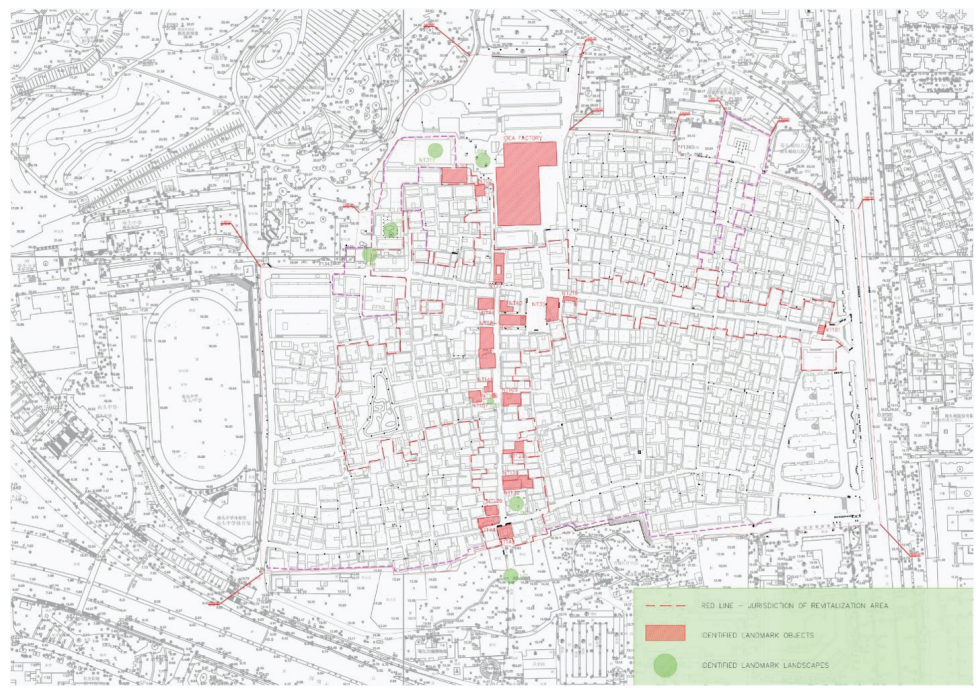

Figure 1. Nantou Ancient Village Landmark Marcation map. Map created by authors 
based on the Urban Research Institute of China Vanke CAD plan. Photo documentation of selected landmarks are available in Appendix iii. Photos are named according to the lot name listed on the map.

\begin{tabular}{|c|c|c|c|c|}
\hline \multicolumn{5}{|c|}{ EXTRACTED USERS BY SELECTED ANSWER +A4:E40ON Q19 } \\
\hline \multicolumn{2}{|l|}{ Landmark parameter } & COLOUR & SHAPE / FORM & TEXTURE \\
\hline \multicolumn{2}{|c|}{ Selection no. (total 53 respondents) } & 8 & 29 & 16 \\
\hline \multirow{2}{*}{ Gender } & male & 1 & 10 & 4 \\
\hline & female & 7 & 19 & 12 \\
\hline \multirow{6}{*}{ Age } & $18-24$ & 4 & 4 & 4 \\
\hline & $25-30$ & 2 & 12 & 5 \\
\hline & $31-40$ & 2 & 13 & 4 \\
\hline & $41-50$ & & & 2 \\
\hline & $51-60$ & & & 1 \\
\hline & $60+$ & & & \\
\hline \multirow{5}{*}{ Degree } & No Educational degree & & 1 & \\
\hline & High School & & 2 & \\
\hline & College & 1 & 3 & 1 \\
\hline & Bachelor & 3 & 12 & 6 \\
\hline & Master or above & 3 & 11 & 9 \\
\hline \multirow{13}{*}{ Occupation } & Civil service & 1 & 12 & 7 \\
\hline & Business & 2 & 1 & 1 \\
\hline & Economics & & 1 & 1 \\
\hline & Language and literature & & 5 & 3 \\
\hline & Arts & 3 & 4 & 1 \\
\hline & Computer Schi \& Tech & & & 2 \\
\hline & Biomedical pharma eng & & & 1 \\
\hline & public management & & 2 & \\
\hline & Law & & 1 & \\
\hline & Philosophy & & 1 & \\
\hline & Light industry \& textile & & 1 & \\
\hline & Education & 2 & & \\
\hline & Transportation & & 1 & \\
\hline \multirow{2}{*}{ Work or live in Nantou } & Yes & 4 & 14 & 8 \\
\hline & No & 4 & 15 & 8 \\
\hline \multirow{3}{*}{ Times of visit } & 1 & 4 & 14 & 10 \\
\hline & $2-5$ & 1 & 10 & 5 \\
\hline & $5+$ & 3 & 5 & 1 \\
\hline \multirow{3}{*}{ Purpose of visit } & Leisure & 7 & 21 & 11 \\
\hline & group gathering & 1 & 3 & 1 \\
\hline & Events & & 2 & 4 \\
\hline \multirow{3}{*}{ Period of visit } & Autumn / Winter 2020 & 4 & 10 & 3 \\
\hline & Winter 2021 & & 1 & 2 \\
\hline & Spring 2021 & 4 & 18 & 11 \\
\hline \multicolumn{2}{|c|}{$\begin{array}{l}\text { First Building to notice (According to the order from } \\
\text { Appendix ii, Power Point research data, P20); } \text { - Image } \\
\text { order no. (x) - User selection }\end{array}$} & $1(5), 11(3)$ & \begin{tabular}{|l|}
$1(7), 3(3), 7(1)$ \\
$8(1), 9(2), 10(3)$, \\
$11(6), 12(1), 13(5)$ \\
\end{tabular} & $\begin{array}{l}1(8,2(1), 3(1), 9 \\
(2), 10(1), 11(3) \\
\end{array}$ \\
\hline \multicolumn{2}{|c|}{$\begin{array}{l}\text { Most favourable building (According to the order from } \\
\text { Appendix ii, Power Point research data, P20); x - Image } \\
\text { order no. (x) - User selection }\end{array}$} & $\begin{array}{l}3(2), 4(1), 10(4) \\
11(1)\end{array}$ & $\begin{array}{l}1(5), 2(1), 3(3), 4(1) \\
5(1), 6(1), 7(1), 9(1) \\
10,11(10), 12(2) \\
13(3)\end{array}$ & $\begin{array}{l}1(2), 3(2), 4(2) \\
9(2), 10(5), 11(2), \\
13(1)\end{array}$ \\
\hline \multicolumn{2}{|c|}{$\begin{array}{l}\text { Considered as most significant landmark (According to } \\
\text { the order from Appendix ii, Power Point research data, } \\
\text { P32); } \mathrm{x} \text { - Image order no. (x) - User selection }\end{array}$} & $\begin{array}{l}1(1), 2(1), 8(1) \\
19(4)\end{array}$ & $\begin{array}{l}1(5), 2(6), 3(2) \\
10(1), 12(1), 14(7) \\
16(2), 17(2), 18(2) \\
19(1)\end{array}$ & $\begin{array}{l}1(1), 2(2), 6(2), \\
8(2), 10(2), 12(1), \\
13(1), 14(3), \\
1 A 46+A 20: E 46+A \\
+A 9: E 46\end{array}$ \\
\hline
\end{tabular}

Figure 2. Extracted respondents' profiles based on landmark parameter selection 
An exploratory study of Nantou Ancient Village revitalisation focusing on visual, cognitive and structural aspects. Jaksa Nikodijevic, Milica Grujic

\section{Discussion}

Gender. Wang et al. (2019) and Kattenbeck (2016) state that females pay more visual attention to landmarks than males. This research has been expanded and it does not only focus on the help provided by landmarks, but also on how their physical characteristics affect the different genders. The results show that physical characteristics and the choice of visual landmarks do not depend on gender, namely, both genders picked shape as the main characteristic, then colour and the smaller percentage chose texture.

Age. Previous research on the effects of age on navigation has shown that adults without dementia are generally less skilled than younger people. (Wilkniss et al., 1997; Moffat et al., 2001). Jansen-Osmann and Wiedenbauer (2004) have shown that the presence of landmarks is more effective on younger people rather than adults. While according to Kattenbeck (2016) age may have a particular impact on the structural salience of objects, Zhong and Moffat (2016) showed that younger individuals outperformed older ones in all tasks except in recognising critical landmarks (critical landmark recognition). The obtained results indicate that the population aged 18-24 chose all physical characteristics as dominant, the population aged 31-40 recognised shape as the dominant parameter of the landmark, while the older population (over 41 years) recognised texture as the dominant parameter.

Education. Berry and de Rosis (1991) reveal that a user's background and job have considerable impact on their knowledge in a domain. Concerning navigation and wayfinding, the education of a traveller may influence the way visual and structural dimensions are perceived (Kattenbeck, 2016). In addition to the level of education, occupation as well as the field of profession are important factors, because people who work in areas such as architecture or the arts receive the visual characteristics of buildings more than people from other fields. This research has been expanded from the connection between the landmark and the educational level to the connection between the physical characteristics of the landmark and the level of education. We found that preference in the physical characteristics of landmarks doesn't depend on the degree of education. All categories of educational degree mostly picked shape as the dominant parameter.

Familiarity. The closer people get to the environment, the more knowledge about space increases (Darken and Sibert, 1996; Thorndyke and Hayes-Roth, 1982; Kelsey, 2009). The question arising focuses on how many times one needs to visit a certain space in order to be considered close to it. At least four visits are the minimum needed in order to not forget the information we learned from that environment (Gärling, Lindberg, and Mäntylä , 1983). Quesnot and Roche (2015) show that people not familiar with an environment prefer landmarks because of their visual or structural salience. But there are also studies that deny the importance of closeness to the environment (Hölscher et al., 2006). This research was not only based on the dependence of proximity to the 
environment and the success of navigation, but also extended to whether proximity to the environment affects the choice of certain characteristics of the landmark. It turned out that all categories of visitors, regardless of the number of visits, chose shape as the main parameter of the landmark.

All previous studies have dealt with the improvement of pedestrian applications and landmarks as application improving tools. (Golledge, 1995; Michon and Denis, 2001; Rehrl et al., 2009; Gartner et al., 2011). This research was based on determining whether visitors of different groups (gender, age, education and closeness to the environment) prefer landmarks or navigation applications as a means of navigation. The results showed that no feature influenced the choice of wayfinding device. Namely, it is especially interesting to note that $100 \%$ of respondents opted for a navigation application as the main tool of the WF, which indicates that navigation applications are the future in finding their way. Additionally, this paper contributed to closer landmark identification in newly revitalised Nantou Old Town.

\section{Conclusion}

In recent years, there has been a growing interest in mobile navigation systems for pedestrians, as this paper has shown. However, these mobile applications can certainly be improved. Given that landmarks are key elements in navigation applications that help pedestrians from point $\mathrm{A}$ to point $\mathrm{B}$, it is important to examine what are landmarks and what the significant visual characteristics that influence their choice are. Our work has contributed to the identification of the landmarks in Nantou Old village, in Shenzhen, which will result in the improvement of navigation applications in this place. The results from this paper, in particular the landmarks rate of selection, will be furthered examined in the specific respondents' categories (gender, age, educational level and familiarity with environment).

\section{Acknowledgments}

This paper and the research behind it would not have been possible without the exceptional support of Anson \& Partners Planning \& Design Consultancy (Shanghai) Ltd., who contributed in providing adequate information, data collection, questionnaire assembly and survey conduct. The generosity and expertise of Professor Jane Zheng at Chinese University in Hong Kong, who has also looked over the paper and was very kind to provide a review report. Special thanks to Urban Research Institute of China Vanke and Yu Le Stevan for providing photo documentation and Nantou revitalisation CAD plans. Last but not least, we are also grateful for the insightful comments offered by the ACAU2021 committee upon our abstract draft handover. 
An exploratory study of Nantou Ancient Village revitalisation focusing on visual, cognitive and structural aspects. Jaksa Nikodijevic, Milica Grujic

\section{References}

Berry, D. C. and de Rosis, F. (1991). Designing an adaptive interface for epiaim, in S. Mario, H. Arie, F. Marius \& T. Jan, eds, 'AIME 91', Springer, 306-316.

Caduf D. and Timpf, S. (2008). On the assessment of landmark salience for human navigation. Cogn Process 9(4), 249-267.

Couclelis, H., Golledge, R.G., Gale, N. and Tobler, W. (1987). Exploring the anchor-point hypothesis of spatial cognition. Journal of Environmental Psychology 7(2), 99-122.

Darken, R. P. and Sibert, J. L. (1996). Wayfinding strategies and behaviors in large virtual worlds. InProceedings of the ACM CHI 96 (pp. 142-149). New York: Association for Computing Machinery.

Gärling, T., Lindberg, E. and Mantyla, T. (1983). Orientation in buildings: Effects of familiarity, visual access, and orientation aids. Journal of Applied Psychology, 68(1), 177-186.

Gartner, G., Huang, H., Millonig, A., Schmidt, M. and Ortag, F. (2011).Human-centred mobile pedestrian navigation systems. Mitteilungen der Österreichischen Geographischen Gesellschaft 153, 237-250

Golledge, R.G. (1995), Path Selection and Route Preference in Human Navigation: A Progress Report. In: Frank, A.U., Kuhn, W. (eds,), Spatial Information Theory - A Theoretical Basis for GIS, pp. 207-222. Berlin/Heidelberg, Springer.

Hölscher, C., Büchner, S., Meilinger, T. and Strube, G. (2006). Map Use and Wayfinding Strategies in a Multi-Building Ensemble. Proceedings International Conference Spatial Cognition, 2006, Lecture Notes in Computer Science (LNCS). Heidelberg: Springer.

Nantou Old Town Preservation and Regeneration. UrbanNext: URBANUS [online]. New York: Actar Publishers, 2018 [cit. 2021-11-25]. Accessible from: https://urbannext.net/nantou-old-town/

Jansen-Osmann, P. and Wiedenbauer, G. (2004). The representation of landmarks and routes in children and adults: A study in a virtual environment, Journal of Environmental Psychology 24(3), 347 - 357.

Kattenbeck, M. (2016). Empirically measuring salience of objects for use in pedestrian navigation. University of Regensburg

Kelsey, S.R. (2009). The" what" and" where" of landmarks: impact on way-finding and spatial knowledge. Carleton University

Lynch, K. (1960). The Image of the City. Cambridge MA: MIT Press.

Michon, P.E. and Denis, M. (2001). When and why are visual landmarks used in giving directions? In: Montello, D.R. (ed.), Spatial Information Theory, pp. 243-259, Berlin, Springer.

Moffat, S. D., Zonderman, A. B. and Resnick, S. M. (2001). Age differences in spatial memory in a virtual environment navigation task. Neurobiol. Aging 22, 787-796. 
doi: 10.1016/S0197-4580(01)00251-2

Nuhn, E. (2020). Modelling of personalised landmarks. Retrieved from https://opus. bibliothek.uni-augsburg.de/opus4/frontdoor/index/index/docId/69864

Ornstein, S. (1992). First impressions of the symbolic meaning connoted by reception area design. Environment and Behavior, 24, 85-110.

Quesnot, T. and Roche, S. (2015). Quantifying the significance of semantic landmarks in familiar and unfamiliar environments, in S. I. Fabrikant, M. Raubal, B. Michela, C. Davies, S. Freundschuh \& S. Bell, eds, 'Spatial Information Theory. COSIT 2015', Vol. 9368 of Lecture Notes in Computer Science, Springer, 468-489

Raubal, M. and Winter, S. (2002). Enriching wayfinding instructions with local landmarks, in M. J. Egenhofer \& D. M. Mark, eds, 'Geographic Information Science. GIScience 2002', Vol. 2478 of Lecture Notes in Computer Science, Springer, 243- 259

Rehrl, K. et al. (2009). An analysis of direction and motion concepts in verbal descriptions of route choices. In: Hornsby, K.S. et al. (eds.), COSIT 2009, pp. 471-488. Berlin/Heidelberg, Springer.

Richter, K.F.and Winter, S. (2014), Computational aspects: how landmarks can be observed, stored, and analysed. Landmarks, pp. 137-173. Springer, Heidelberg

Siegel, A. and White, S. (1975). The Development of Spatial Representations of LargeScale Environments. Advances in Child Development and Behavior,10, 1975, 9-55.

Sorrows, M.E. and Hirtle, S.C. (1999) The nature of landmarks for real and electronic spaces. In: International conference on spatial information theory, pp 37-50. Springer, Berlin.

Thorndyke, P. W. and Hayes-Roth, B. (1982). Differences in Spatial Knowledge Acquired from Maps and Navigation. Cognitive Psychology, 14, 560-589.

Wang, C., Chen, Y., Zheng, S. and Liao, H. (2019). Gender and age differences in using indoor maps for wayfinding in real environments, ISPRS International Journal of Geo-Information 8(11), 1-20

Weisman, G. D. (1979). Way-finding in buildings, Ph.D. dissertation, University of Michigan, College of Architecture and Urban Planning.

Wilkniss, S. M., Jones, M. G., Korol, D. L., Gold, P. E. and Manning, C. A. (1997). Age-related differences in an ecologically based study of route learning. Psychol. Aging 12, 372-375. doi: 10.1037/0882-7974.12.2.372

Winter, S., Janowicz, K., Richter, K.-F. and Vasardani, M. (2012). Knowledge acquisition about places, SIGSPATIAL Special 4(3), 20-21.

Zhang, H. (2008). Shenzhen: Frontier City. In China Design Now, edited by Parker, Lauren and Zhang Hongxing. London: V \& A Publishing.

Zhong, J.Y. and Moffat, S.D. (2016). Age-related differences in associative learning of landmarks and heading directions in a virtual navigation task Front. Aging Neurosci., 8 , p. 122 
22 An exploratory study of Nantou Ancient Village revitalisation focusing on visual, cognitive and structural aspects. Jaksa Nikodijevic, Milica Grujic

\section{QUESTIONAIRRE}

ONLINE SURVEY IN CHINESE: https://www.wenjuan.com/s/UZBZJv4jKZ/

PURPOSE: PERFORMANCE EVALUATION OF REVITALIZED NANTOU ANCIENT VILLAGE IN SHENZHEN

Researchers: Milica Grujic, Jaksa Nikodijevic

1. Gender:

$\square$ Female; $\square$ Male

2. Age:
$\square<18$;
$\square$ 18-24;
$\square 25-30 ;$
$\square 31-40$
$\square 41-50$
$\square 51-60 ;$
口61+;

3. Educational degree:

$\square$ No degree; $\square$ Elementary school; $\square$ High school; $\square$ College; $\square$ Bachelor Degree; $\square$ Master or above

4. University Major:

5. Occupation:

6. Are you in any form linked to every day life in Nantou Ancient Village (Work or living)?

$\square$ Yes; $\square$ No

7. How many times you visited Nantou Ancient Village in period after Autumn 2020?

$\square 1 ; \square 2-5 ; \quad \square 5+$

8. Purpose of visit (In period after Autumn 2020)?

$\square$ Leisure / Site seeing; $\quad \square$ Event; $\quad \square$ group gathering; $\square$ others

9. Period of visit?

$\square$ Autumn/Winter 2020; $\quad \square$ Winter 2021; $\quad \square$ Spring 2021

10. Mark below which describes best renovated Nantou Ancient Village (Multiple answers are acceptable):

$\square$ Heritage site; $\quad \square$ Modern; $\quad \square$ Artistic; $\square$ Creative Cluster; $\quad \square$ Tourist site;

$\square$ Commercial; $\quad \square$ Others - Describe:

11. Mark how successful is revitalization of Nantou Village

$\square$ Very successful; $\quad \square$ Somewhat successful; $\quad \square$ Not successful

12. The new Nantou visual experience of yours is:

$\square$ Unique; $\quad \square$ Impression of mixed cultures, designs and functions; $\quad \square$ Generic

13. Mark the quality of orientation and site finding inside Nantou Ancient Village?
$\square$ Easily understandable;
$\square$ Somewhat understandable;
$\square$ Complicated. 
14. Mark no more than two items below which you find to be best meeting/gathering point at Nantou Ancient Village:
$\square$ South Gate;
$\square$ East Gate;
$\square$ Square (any);
$\square$ Temple;
口 IDEA FACTORY
$\square$ other - State location:

15. Does any of these landmarks from Q9 helps your orientation or wayfinding?

$\square$ Yes; $\square$ No

16. If the answer on Q10 is "Yes", kindly name which landmark you are referring to: Landmark:

17. Mark which zones on the map have you visited?

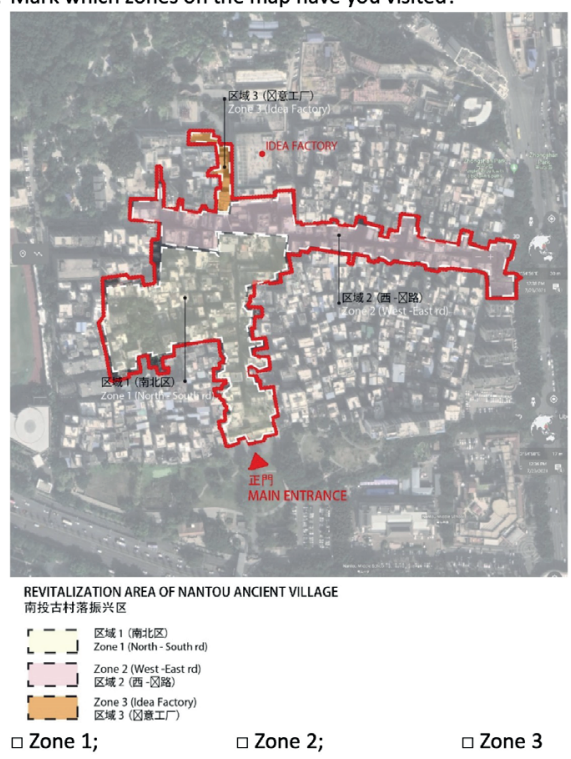

18. Select the image of the building that you notice firstly:

IMAGES IN APPENDIX ii

19. Select the image of the building from Q13 that you find most attractive: 
24 An exploratory study of Nantou Ancient Village revitalisation focusing on visual, cognitive and structural aspects. Jaksa Nikodijevic, Milica Grujic

20. What is most important parameter or reason to your choice on Q14?

$\square$ Color; $\quad \square$ Shape/Form; $\square$ Texture and pattern;

$\square$ Others - State:

21. Which building, object or landscape feature elements from the images below you find to be Nantou Landmark (up to 2 choices)?

IMAGES IN APPENDIX ii

22. Which functions you think are missing at the Nantou Ancient Village?

$\checkmark$ Cinema; $\square$ Concert/Performance hall; $\square$ Sports; $\square$ Educational institutions

$\square$ Others:

23. Do you think there are sufficient Signage mapping on site for way finding? $\square$ Yes; $\square$ No

24. What method did you use for orientation and site finding inside Nantou Ancient Village? $\square$ Any navigation app or map; $\square$ Location landmarks;

口 Others:

25. If you have any additional comment about visual and functional impact of Nantou Ancient village revitalization, kindly write down in following box:

Thank you for helping the research.

APPENDIX i - questionairre - NANTOU Ancient Village revitalization 3/3 

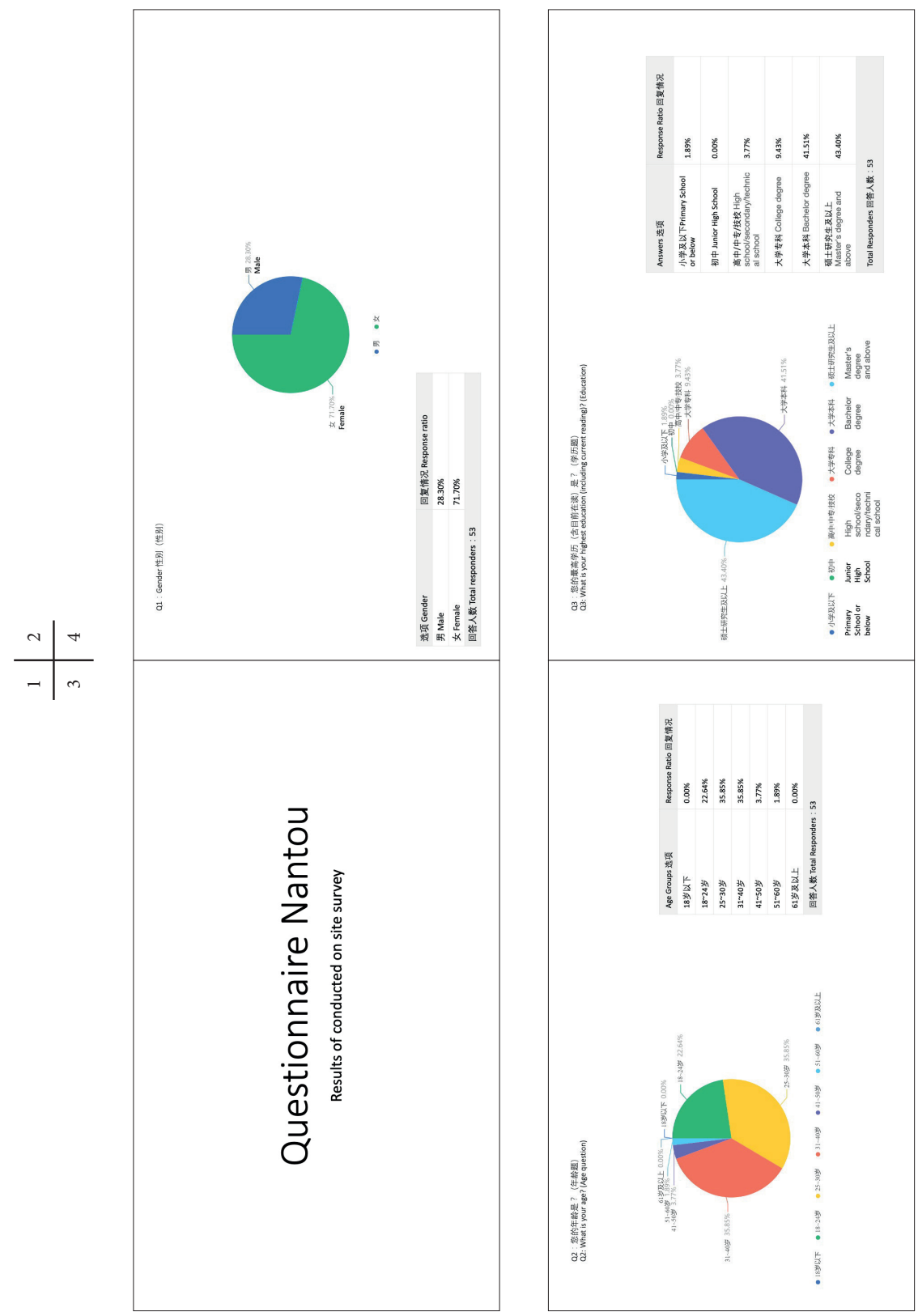

APPENDIX ii - NANTOU Survey research results 

visual, cognitive and structural aspects. Jaksa Nikodijevic, Milica Grujic
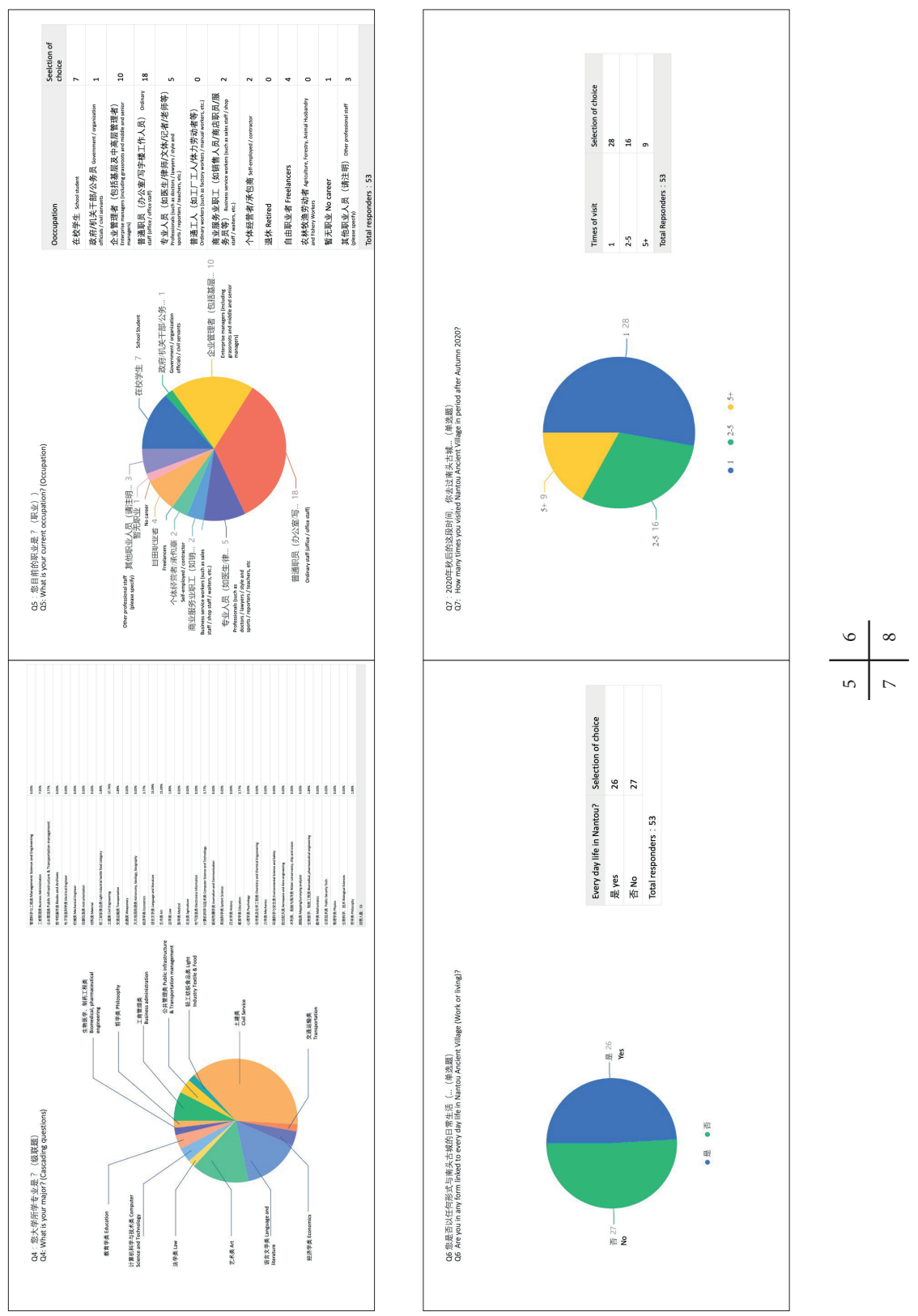

APPENDIX ii - NANTOU Survey research results 

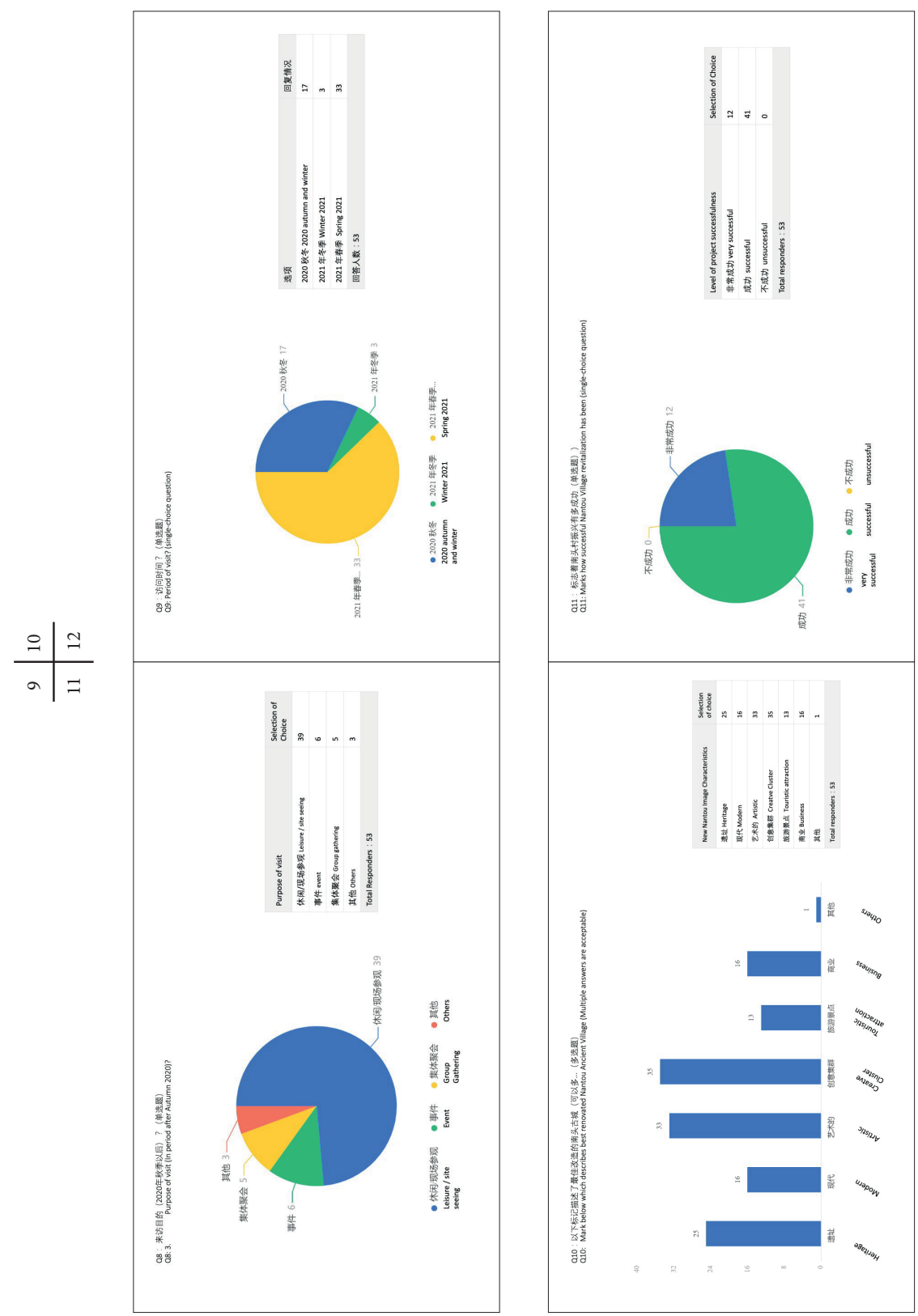

APPENDIX ii - NANTOU Survey research results 

visual, cognitive and structural aspects. Jaksa Nikodijevic, Milica Grujic
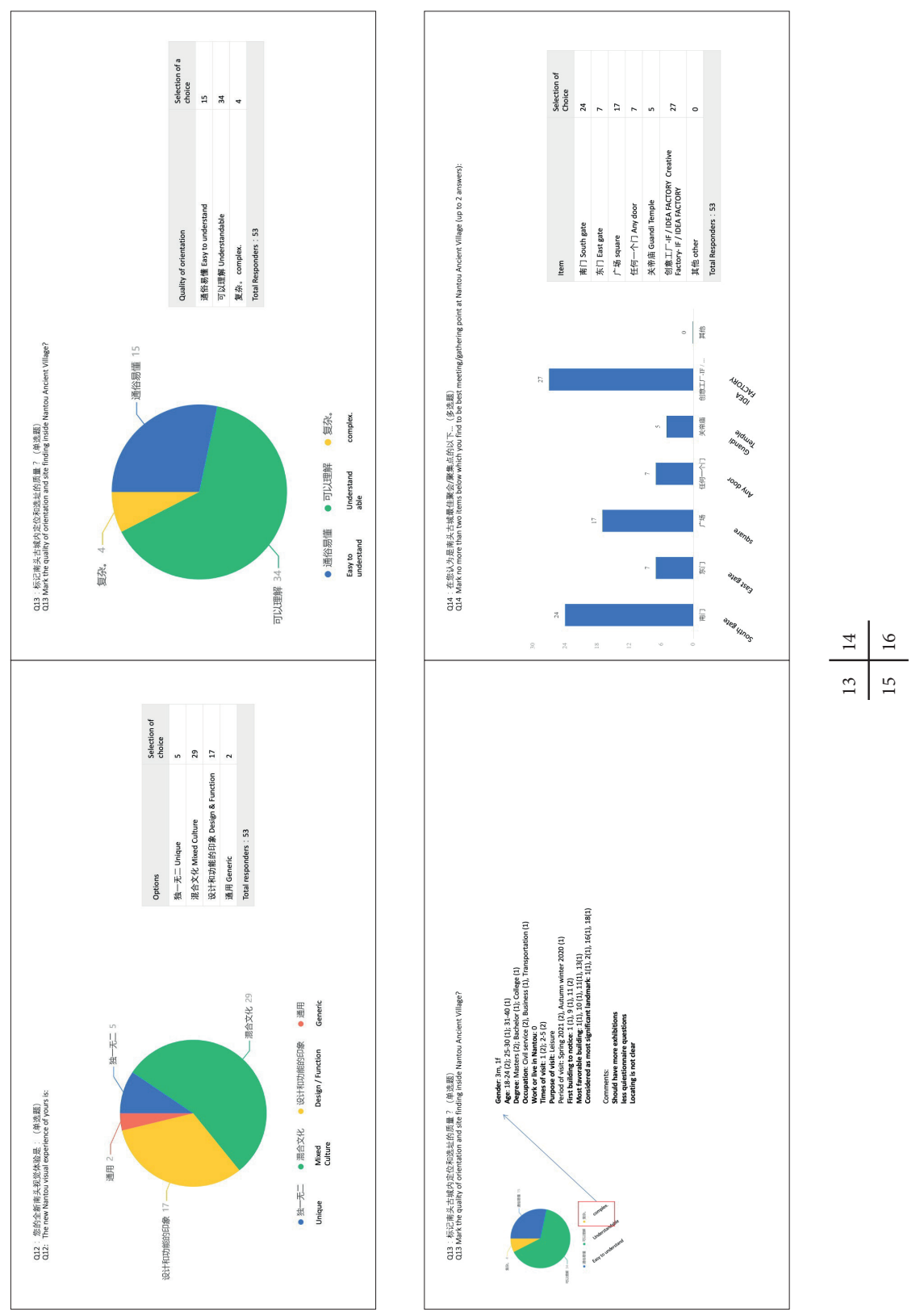

APPENDIX ii - NANTOU Survey research results 

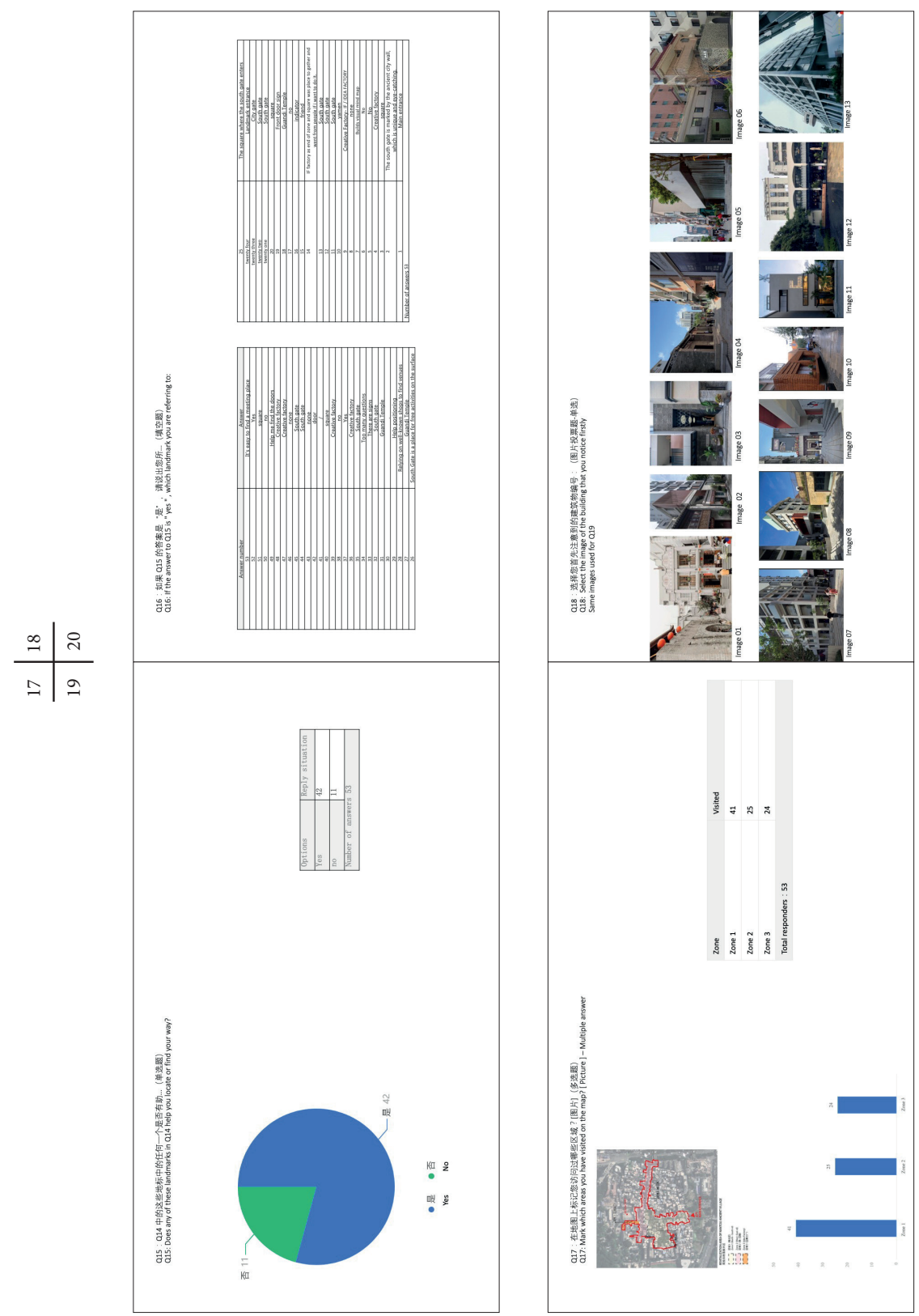

APPENDIX ii - NANTOU Survey research results 

visual, cognitive and structural aspects. Jaksa Nikodijevic, Milica Grujic
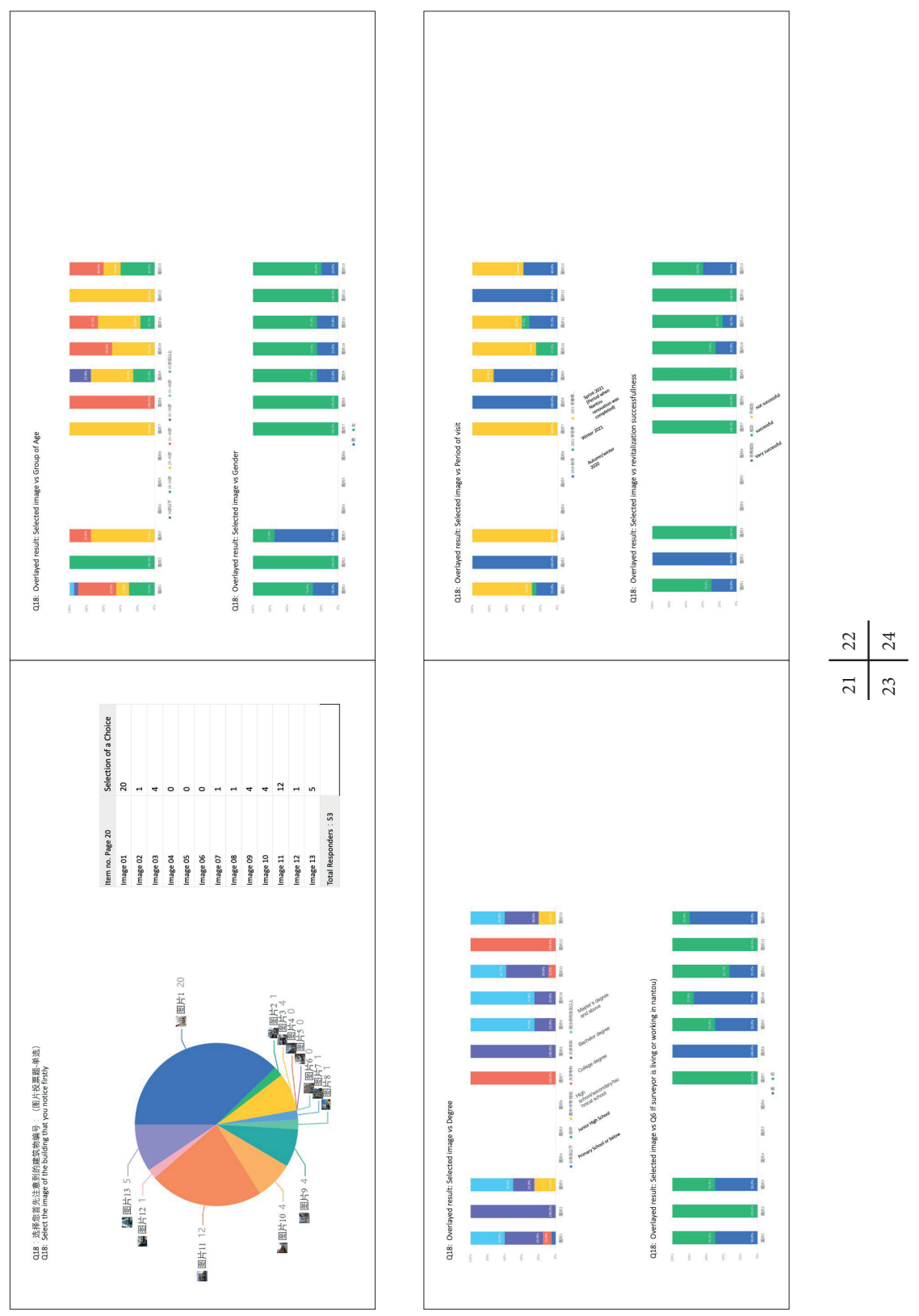

APPENDIX ii - NANTOU Survey research results 

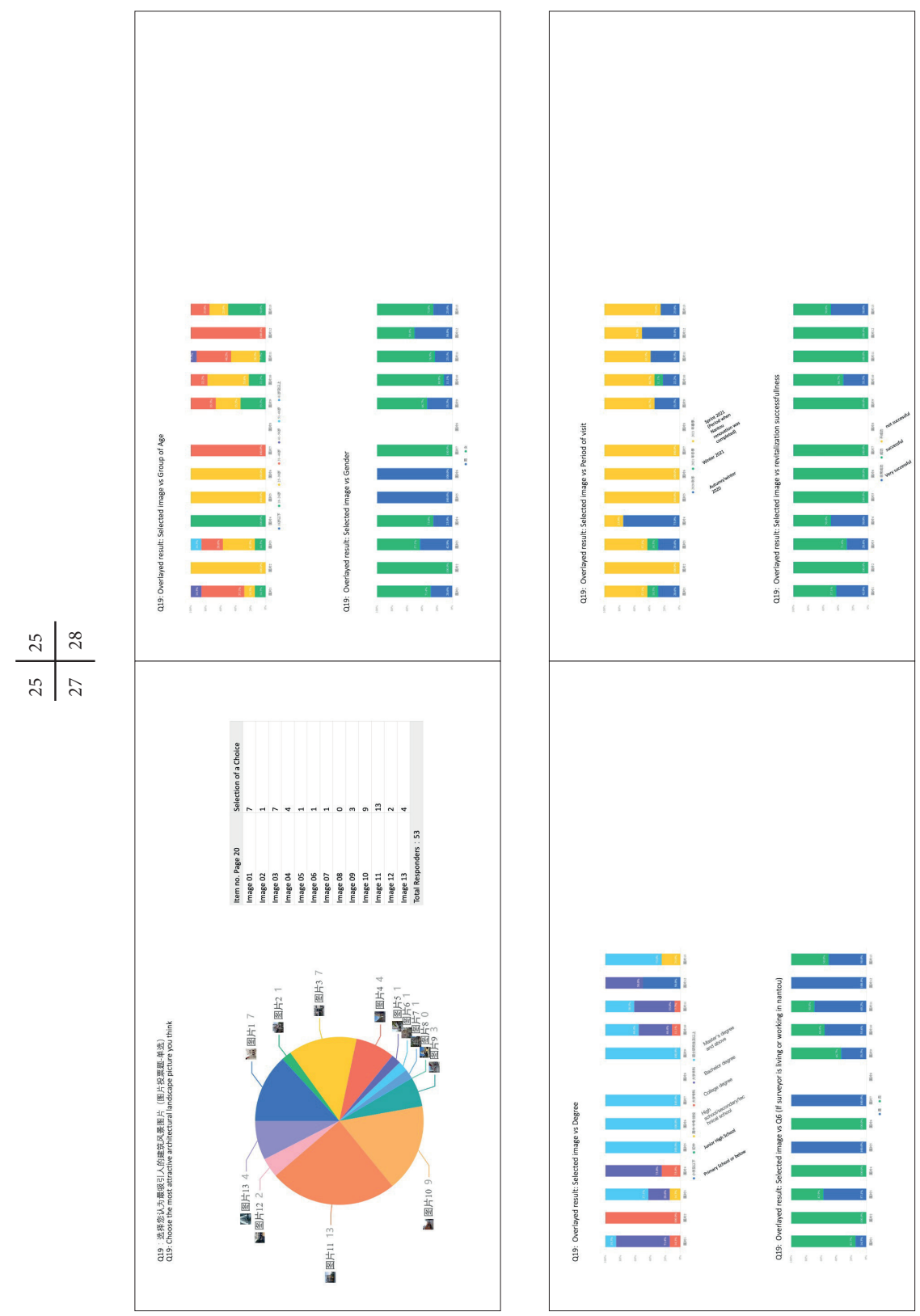

APPENDIX ii - NANTOU Survey research results 

visual, cognitive and structural aspects. Jaksa Nikodijevic, Milica Grujic
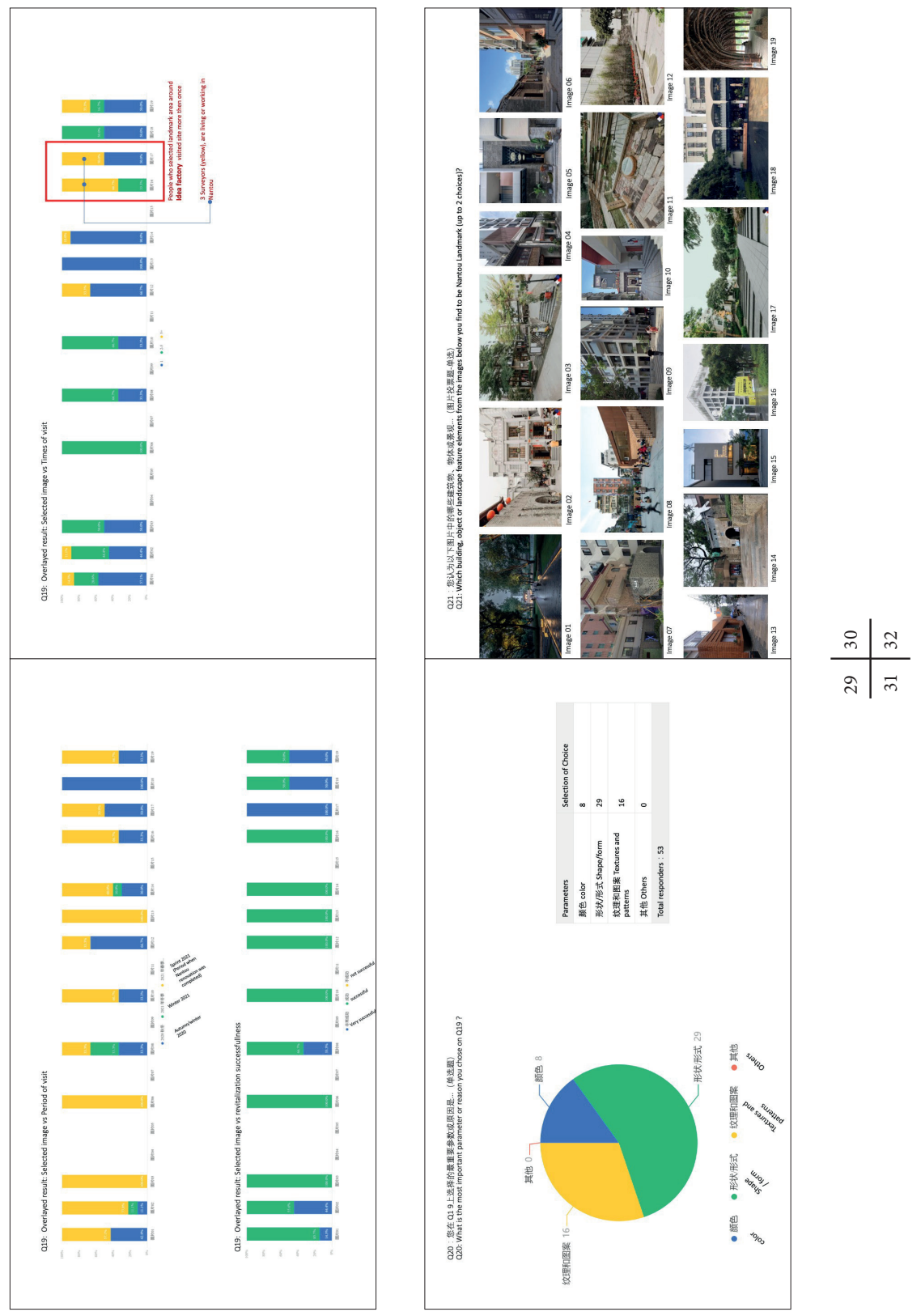

APPENDIX ii - NANTOU Survey research results 

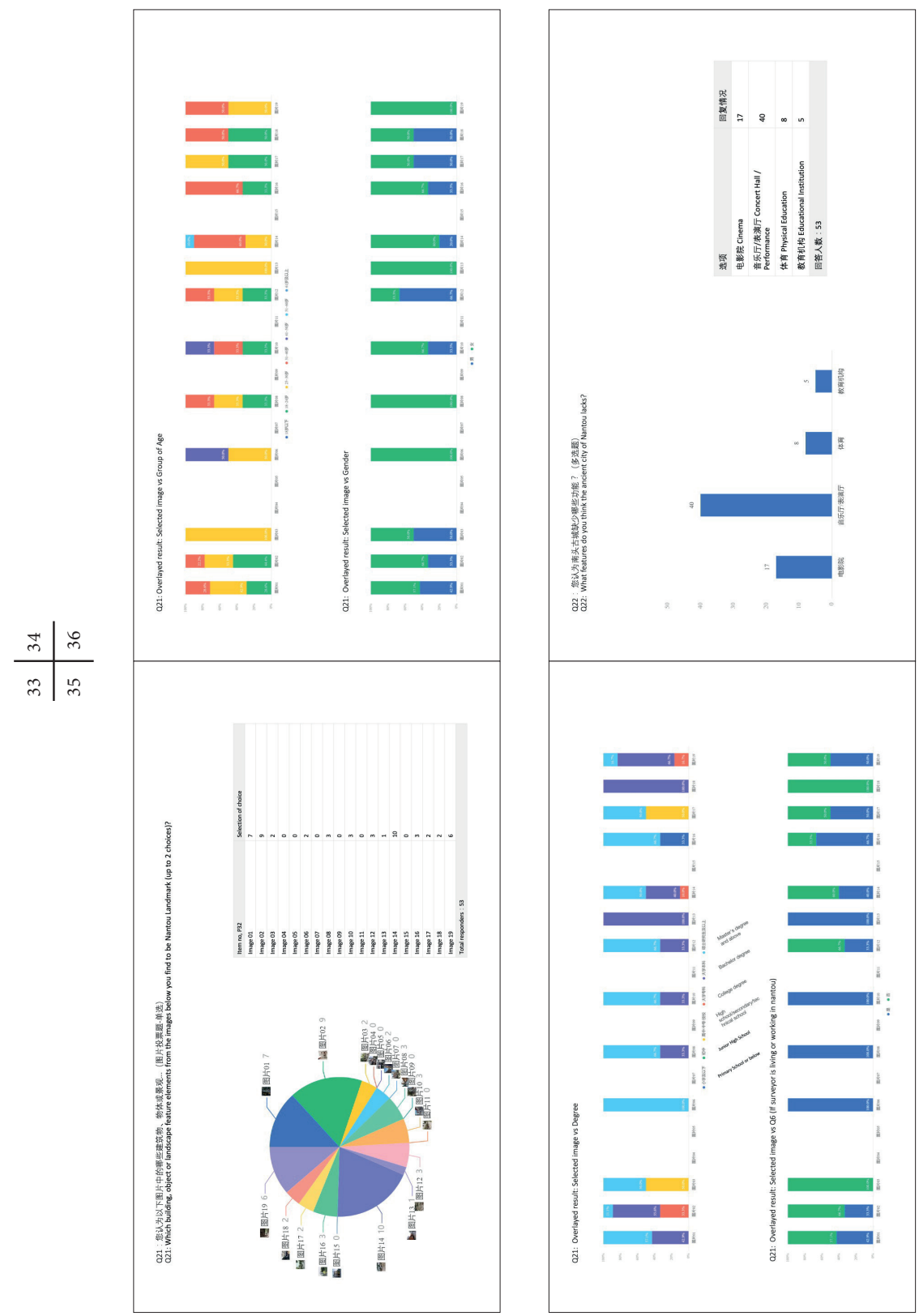

APPENDIX ii - NANTOU Survey research results 

visual, cognitive and structural aspects. Jaksa Nikodijevic, Milica Grujic
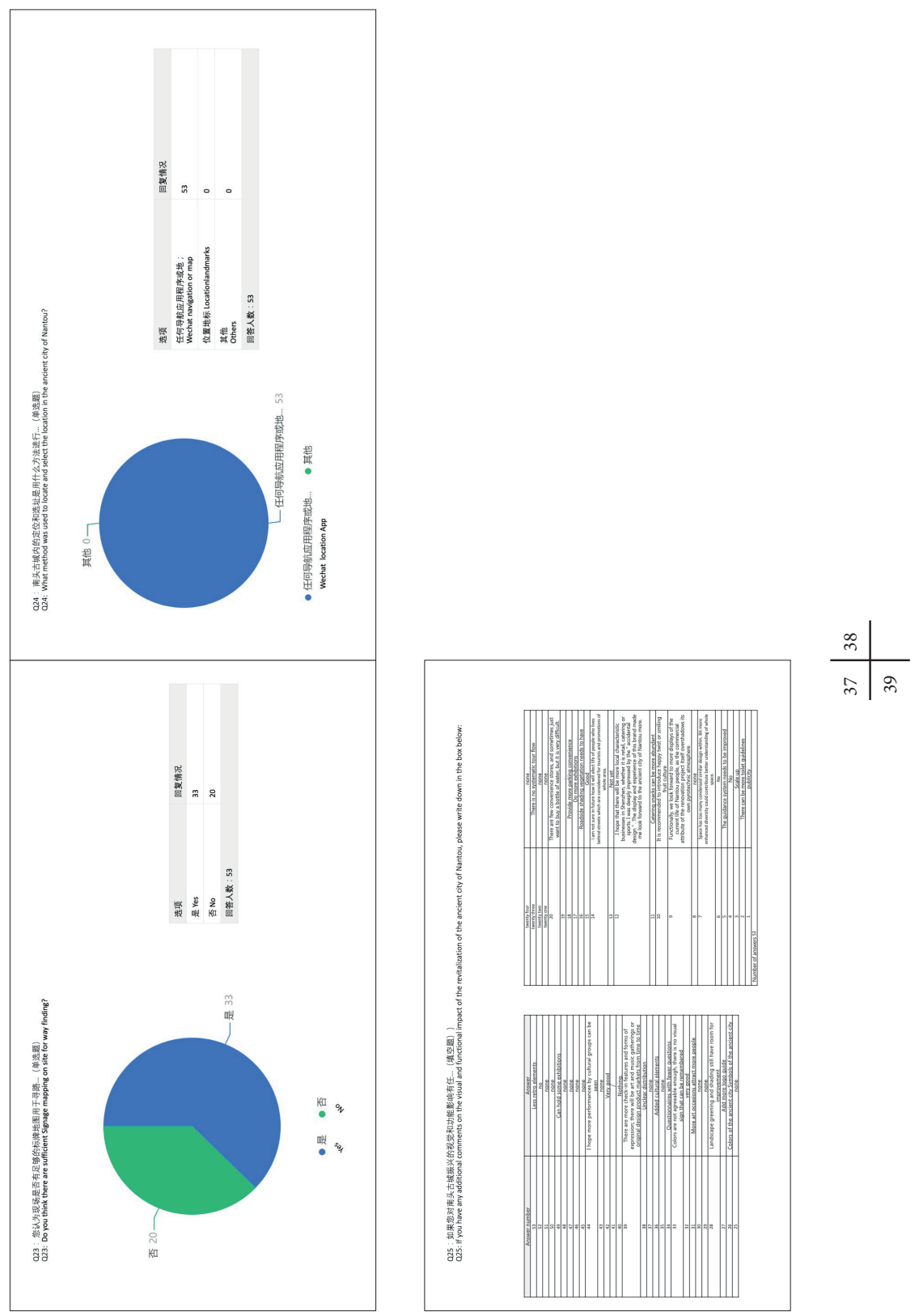

APPENDIX ii - NANTOU Survey research results 

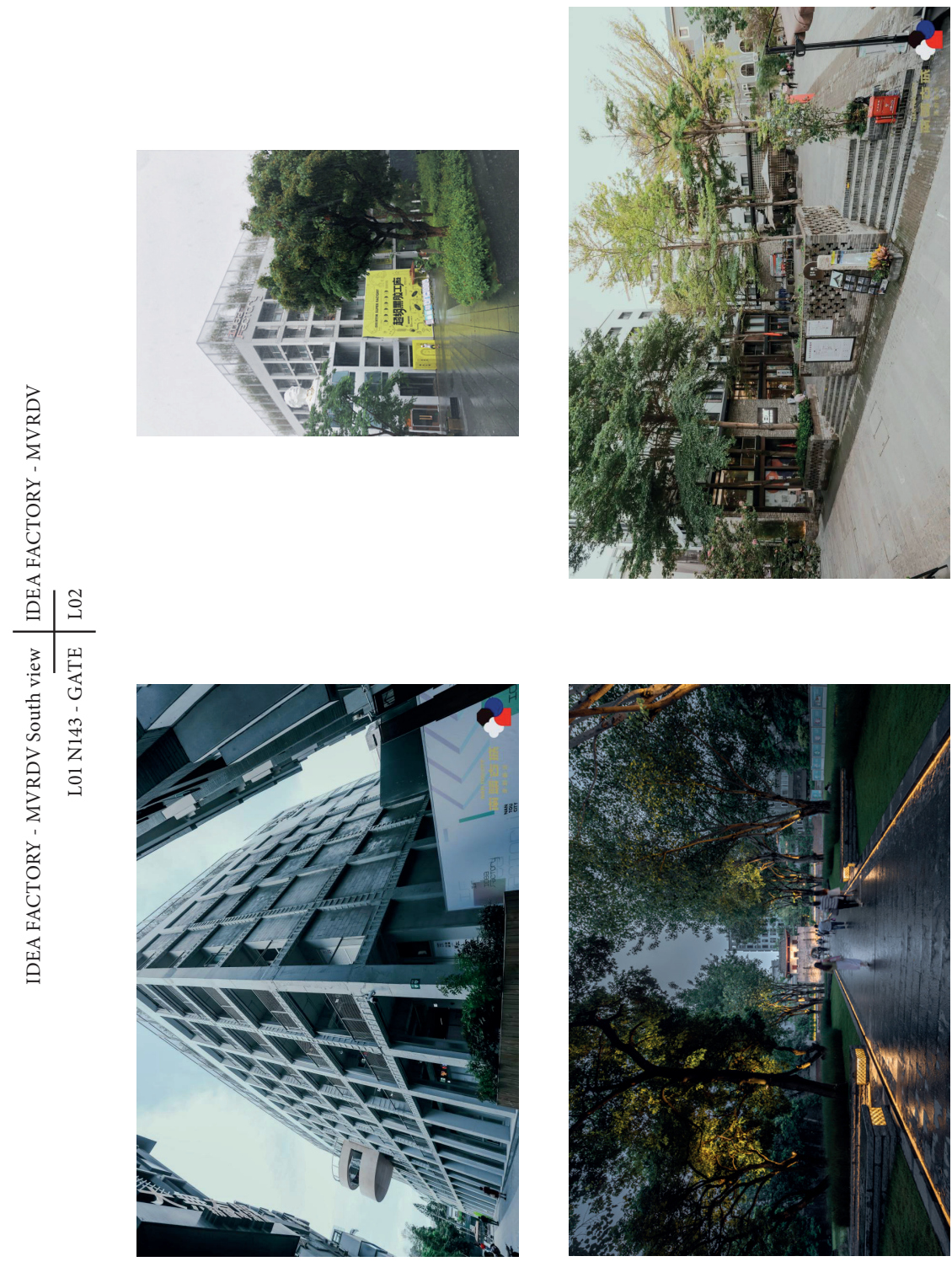

APPENDIX iii - Landmark Image Gallery 

visual, cognitive and structural aspects. Jaksa Nikodijevic, Milica Grujic
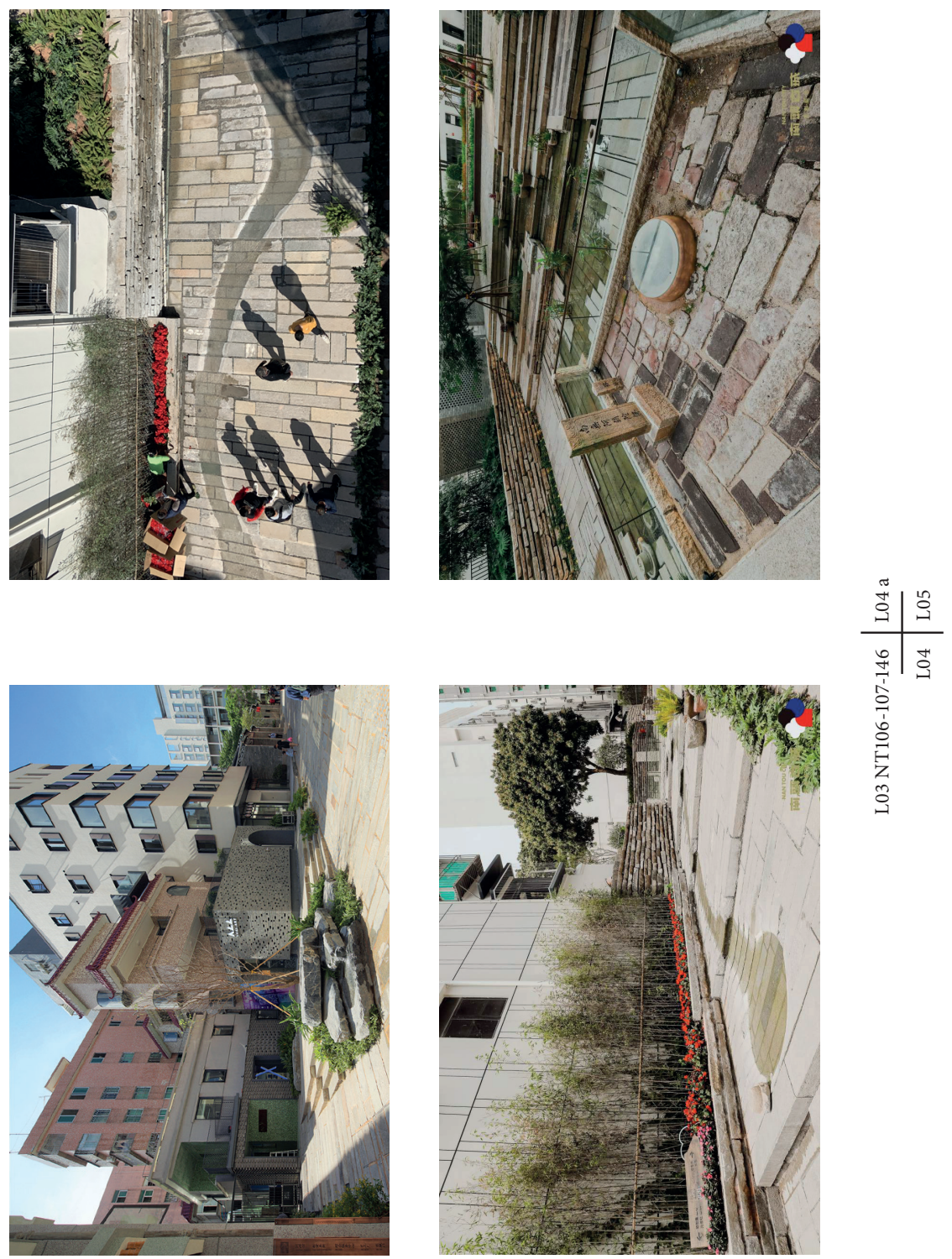

APPENDIX iii - Landmark Image Gallery 

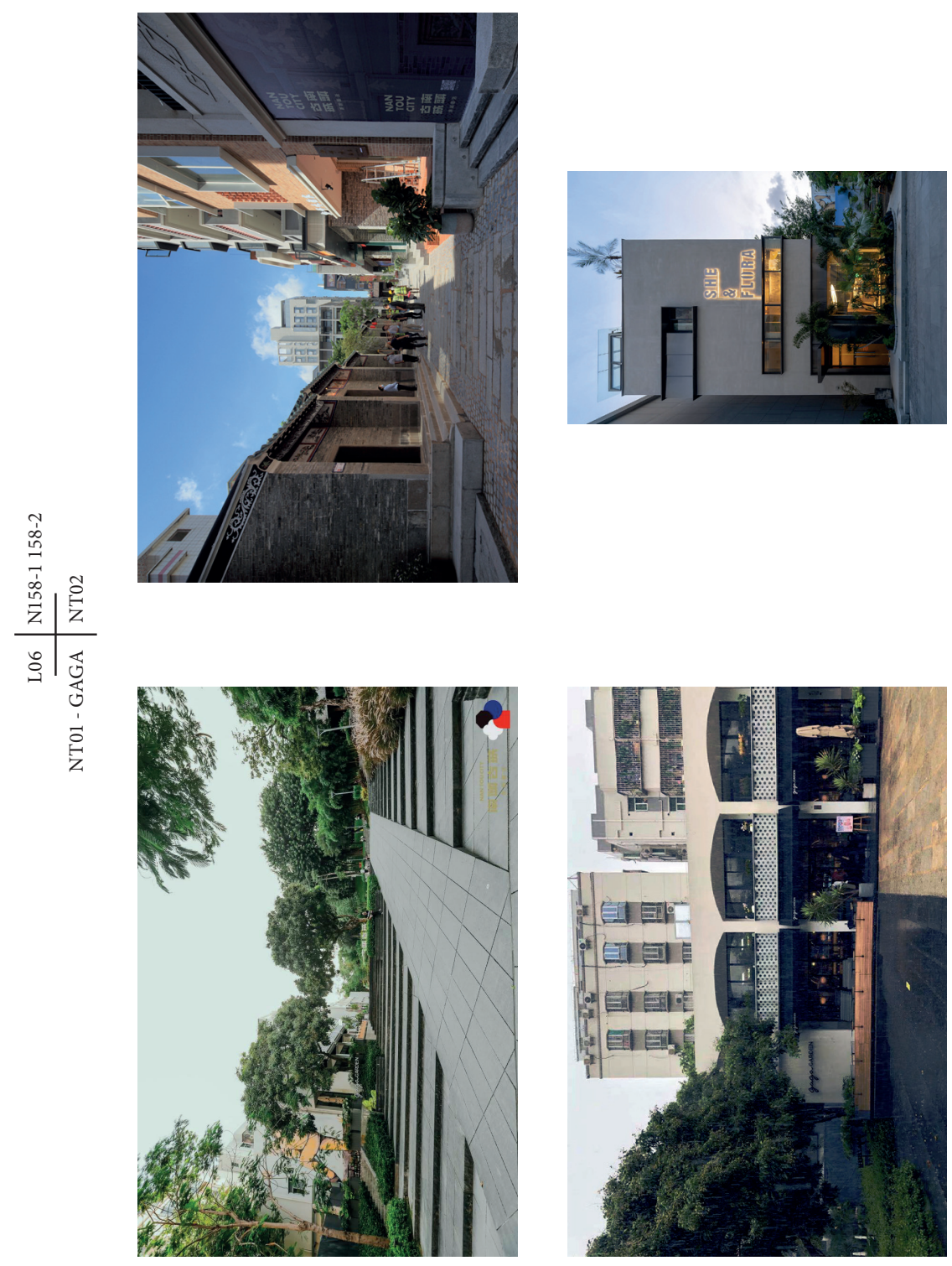

APPENDIX iii - Landmark Image Gallery 

visual, cognitive and structural aspects. Jaksa Nikodijevic, Milica Grujic
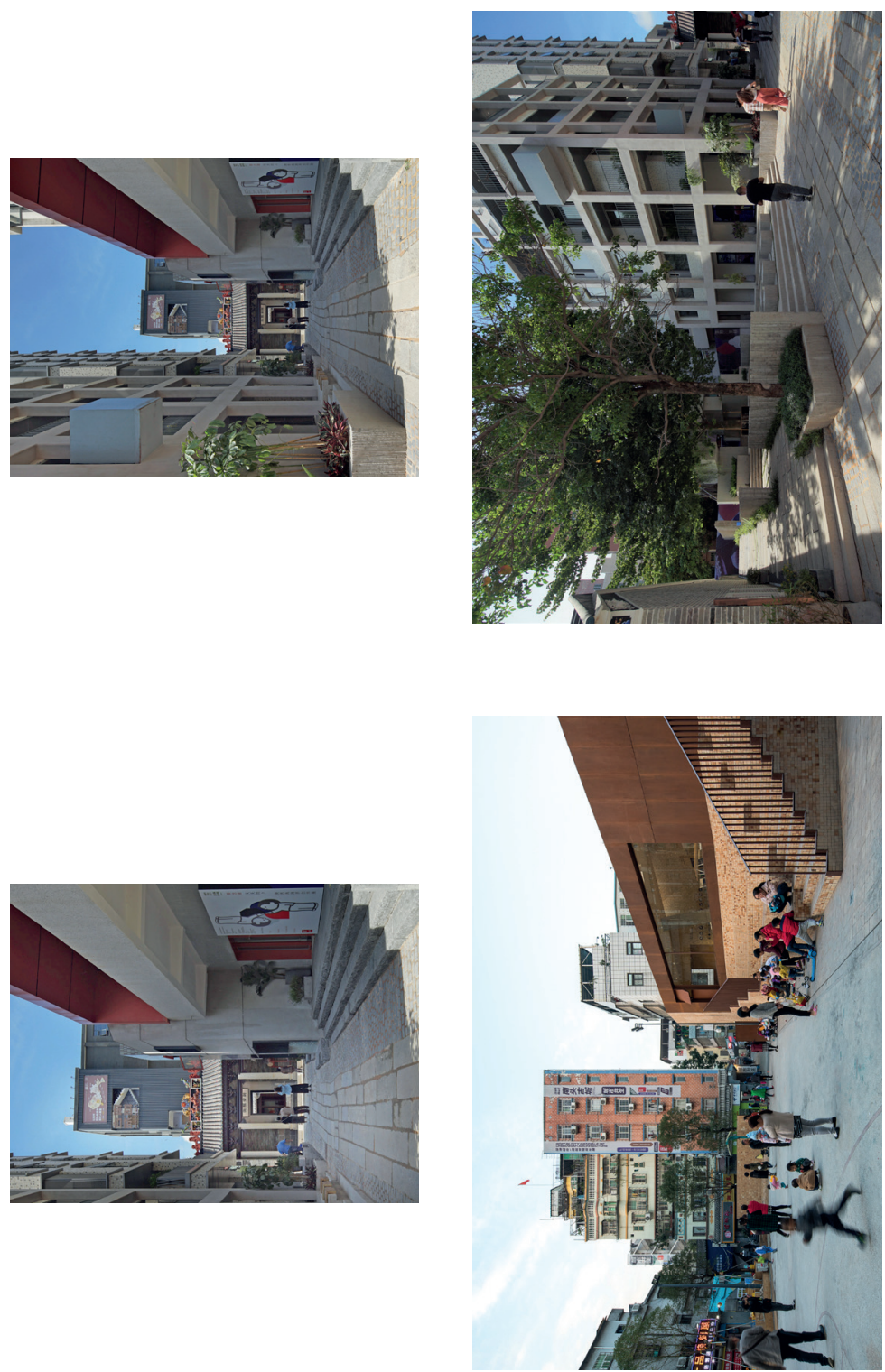

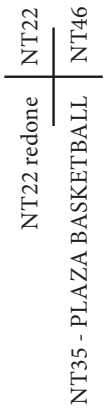

APPENDIX iii - Landmark Image Gallery 

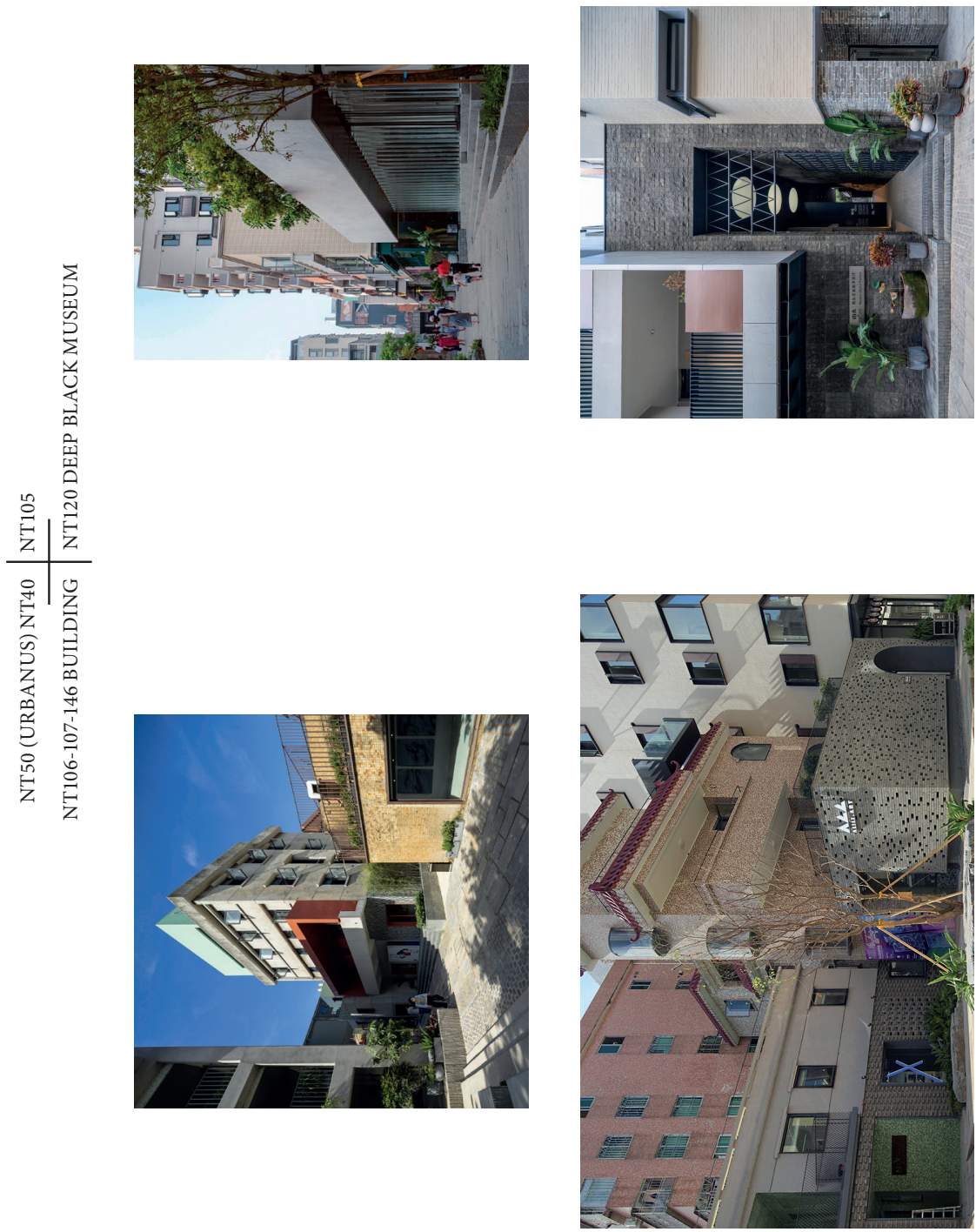

APPENDIX iii - Landmark Image Gallery 
An exploratory study of Nantou Ancient Village revitalisation focusing on visual, cognitive and structural aspects. Jaksa Nikodijevic, Milica Grujic
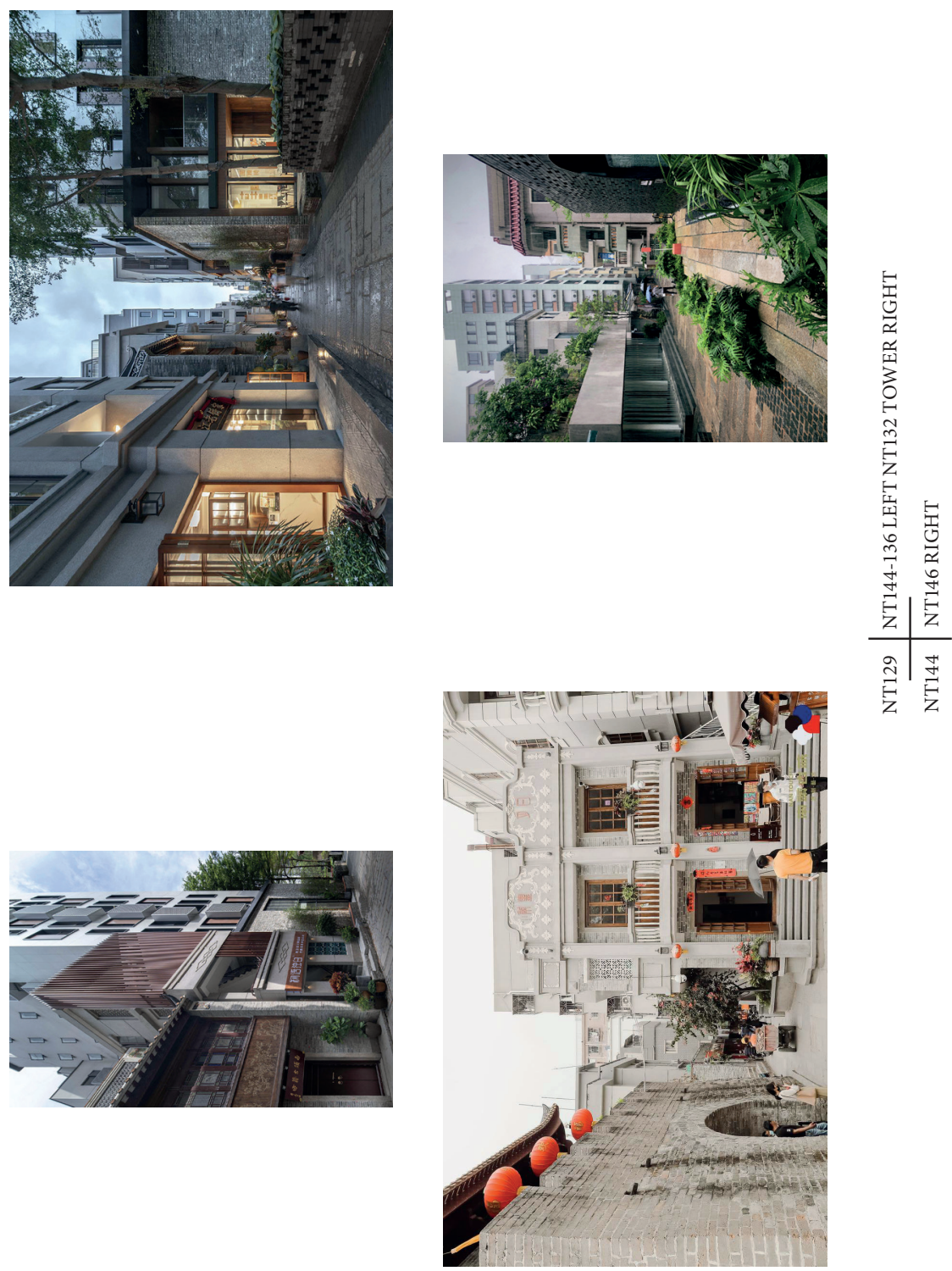

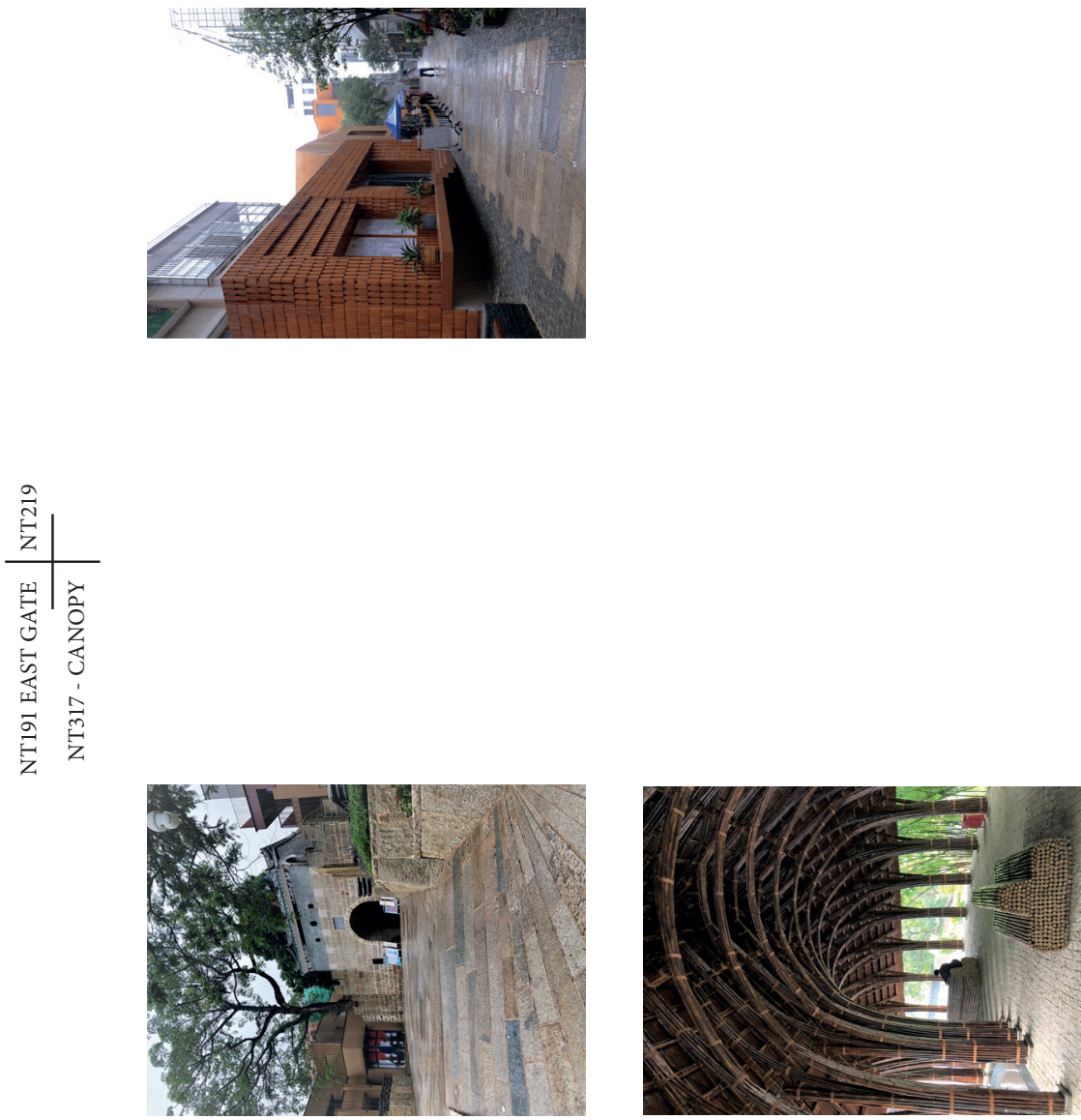

APPENDIX iii - Landmark Image Gallery 